\title{
Design aspects of a deployable tensegrity-hollow-rope footbridge
}

\author{
L. Rhode-Barbarigos ${ }^{1}$ N. Bel Hadj Ali ${ }^{1}$, R. Motro ${ }^{2}$, I.F.C. Smith ${ }^{1}$
}

1 IMAC Ecole Polytechnique Fédérale de Lausanne

2 Laboratoire de Mécanique et Génie Civil, LMGC, Montpellier

\begin{abstract}
Tensegrity structures are composed of cables and struts in a pre-stressed self-equilibrium. Although tensegrity first appeared in the 1950s, it is seldom used in civil engineering. This paper focuses on the design aspects of a deployable tensegrity-hollow-rope footbridge. Deployment is usually not a critical design case for traditional deployable structures. However, for tensegrity systems deployment may be critical due to the actuation required. In this paper, deployment is investigated in a general design framework. The influence of clustered (continuous) cables and spring elements in statics and dynamics is studied. Finally, actuation schemes are explored to identify cases where deployment becomes a critical design case. For this configuration, deployment is a critical design case when the structure has spring elements and continuous cables.
\end{abstract}

Keywords :tensegrity-ring, footbridge, deployment, dynamic, actuators, control

1. Introduction

The concept of tensegrity was first introduced in the 1950s. Tensegrity describes reticulated self-equilibrated systems composed of unidirectional loaded structural components. Tensegrity became popular with the work of Kenneth Snelson and its peculiar sculptures of floating struts [1]. Nowadays tensegrity systems are defined as: "systems in stable selfequilibrated state comprising a discontinuous set of compressed components inside a continuum of tensioned components" [2]. Consequently, tensegrity systems are in a stable self-equilibrium requiring no external forces. Compressive components may be composed of one or more struts. Skelton et al. [3] proposed a "class $k$ " distinction based on the number $k$ of interconnected struts.

Tensegrity structures are spatial pre-stressed structures composed of struts and cables with pin-jointed connections. The self-stressed equilibrium among struts and cables guarantees stability and stiffness for a predefined topology leading to relatively lightweight structures compared with other structural systems with the same load-bearing capacity. The relatively large load-bearing capacity of tensegrity structures is due to their ability to distribute loading among components in the system but also due to their efficient use of material: struts for compression only and cables for tension [4].

Although tensegrities have been seen as attractive modular solutions for architects and engineers for decades now, they are rarely used in practice [5-8]. Moreover, designing a tensegrity structure is a challenging task due to a complex coupled nonlinear behavior that is closely related to the topology explored. Furthermore, there are no generally accepted design guidelines for tensegrity structures except a few studies underlying critical parameters of their structural behavior such as self-stress and the strut-to-cable stiffness ratio [9, 10]. Due to the 
complexity of the design task, the use of stochastic search methods or other optimization techniques has been explored [10,11]. However, no study takes into account shape changes such as deployment and actuation schemes for the design of the tensegrity structure.

Tensegrity structures are advantageous systems also due to their control capability. Both struts and cables can be used as actuators and/or sensors in a tensegrity system [12,13]. Actuation is thus embedded within the system transforming a stable tensegrity system into a dynamic system that can interact with its environment enhancing performance by changing shape or properties such as stiffness. An example of an active tensegrity structure enhancing service performance with the use of telescopic struts and advanced informatics was studied in [14, 15]. Active control was also used for damage tolerance and vibration control [16, 17]. However, no large shape changes such as in deployment were considered. Moreover, tensegrity systems require small amounts of energy for control [3]. Therefore, active tensegrity systems are good candidates for deployable structures where large shape changes are usually required.

Deployment describes a large shape change: from a compact configuration to an expanded operational one [18]. Most deployable systems are based on single-degree-of-freedom (SDOF) mechanisms such as scissor-like elements [19]. Although SDOF mechanisms are easy to control, they are usually not stiff during deployment; additional members are required to increase their stiffness for loading. Tensegrity systems, however, are multi-degree-offreedom (MDOF) systems requiring actuated members (members that change length) to change their shape. If deployment requires large length changes, cable actuation is usually more efficient than strut actuation.

Deployable tensegrity structures were first introduced by Furuya [20] who studied the deployment of tensegrity masts. Sultan and Skelton [21] showed that cable actuation allows a better control of the deployment of tensegrity structures as it allows the structure to remain close enough to their equilibrium manifold. Thus, tensegrity systems can maintain their stiffness throughout deployment in contrast with traditional deployable systems that are stiff only at their folded and unfolded configurations. Smaili and Motro [22] studied the deployment of a double layer tensegrity grid through a series of finite mechanisms created using cable-length changes. Although various actuation schemes have been studied for deployable tensegrity systems, no scheme explored clustered cables with spring elements for the deployment of a tensegrity footbridge-system. Clustered cables are continuous cables that run over frictionless pulleys. Moreover, no study takes into account deployment along with the traditional civil engineering criteria of safety and serviceability for the design of a tensegrity structure. 

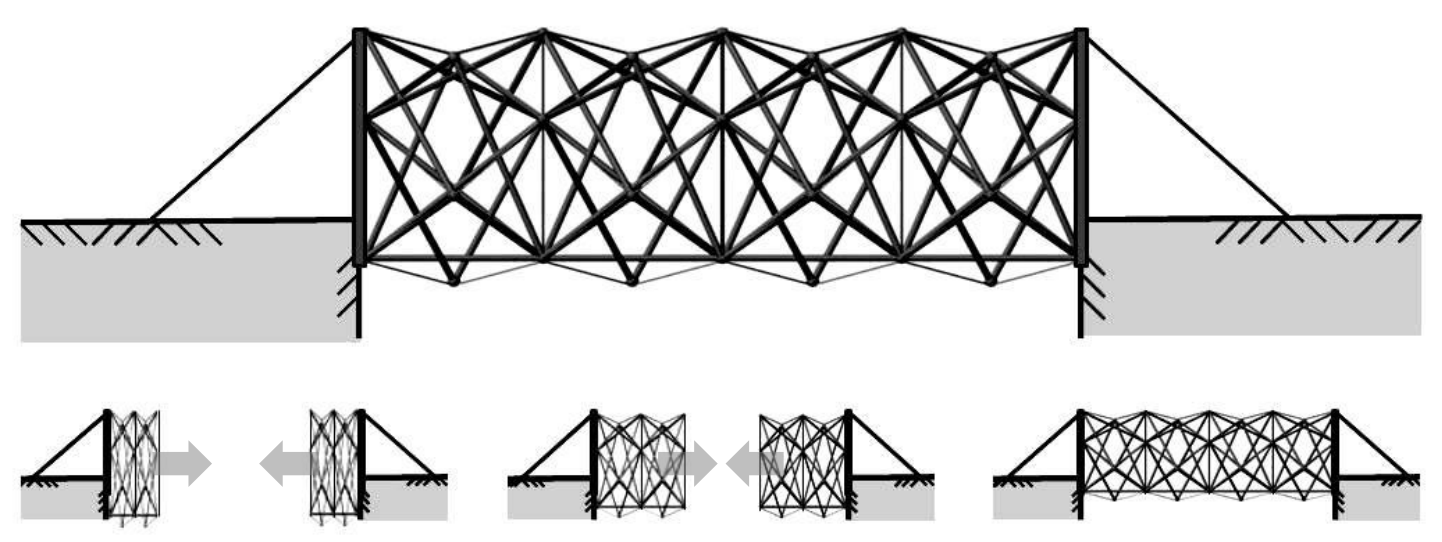

Figure 1: Illustration of the pentagonal tensegrity-ring deployable footbridge system.

This paper focuses on the design of a deployable tensegrity-hollow-rope footbridge including static, dynamic and deployment aspects. The structure is composed of four pentagonal tensegrity-ring modules (Figure 1). The deployment of the tensegrity footbridge is controlled using actuated cables. Cable-actuation is explored for a contact-free deployment of the tensegrity structure. The structure is assumed composed of steel hollow tubes and steel cables designed according to the Swiss codes SIA including both static and dynamic criteria. Static analysis is performed using a modified dynamic relaxation algorithm, while dynamic analysis is performed based on a linearized dynamic model.

Three actuation schemes are analyzed for deployment. The first scheme employs individually actuated cables only while the second combines individually actuated cables with clustered (continuous) actuated cables. The third scheme employs clustered actuated cables with spring elements. Clustered actuated cables and spring elements are employed to decrease the number of actuators required thus reducing complexity in design, control and cost of the structure. Deployment is assumed to be a series of intermediate equilibrium configurations with different system lengths. It is thus analyzed using the dynamic relaxation method. Cases where deployment is critical for the design are identified.

\section{The tensegrity-ring footbridge}

Tensegrity-ring modules were first presented in 1976 by Pugh [23]. They are class II tensegrity systems with strut-to-strut connections arranged in a ring configuration. These systems were named "ring modules" by Motro et al. [24]. Interconnected struts in ring modules create a single strut circuit that can be described using straight prism geometry. Prism geometry defines ring-module topology including the number of struts and cables. This study focuses on pentagonal ring-module topology. The pentagonal tensegrity-ring module contains 15 struts and 30 cables.

Tensegrity systems are characterized by the number of infinitesimal mechanisms and selfstress states. Singular Value Decomposition (SVD) of the equilibrium matrix of a self-stressed pentagonal ring module reveals that it has no infinitesimal mechanisms and six independent states of self-stress $[25,26]$. The structural behavior of a pentagonal ring module under tension, compression and bending was studied in [26, 27]. However, the referenced study focused on a single module with unclustered cables; no cable continuity was employed. 
Clustered cables affect tensegrity mechanics by reducing kinematic constraints and modifying the internal force distribution since continuous cables are assumed to carry equal tension in all segments running over frictionless pulleys [28].

The deployable tensegrity footbridge is composed of four identical pentagonal ring modules connected together in a "hollow-rope" system, where the empty space in their center is used as walking space with the addition of a deck. The hollow-rope tensegrity system was found viable for a tensegrity footbridge [29, 30]. However, clustered cables, spring elements and deployment were not taken into account. In this study, each module has a span of $4 \mathrm{~m}$ and a diameter of approximately $6.2 \mathrm{~m}$. Furthermore, deployment is assumed from both sides joining in the middle as shown in Figure 1. During deployment, nodes of the structure at both extremities are assumed blocked only along the longitudinal axis of the footbridge. During service, boundary nodes are assumed to be fixed in all three translation directions.

The four-module hollow-rope tensegrity system is a class IV tensegrity system with 60 struts and 110 cables (cables at midspan need to be doubled if deployment is assumed from both sides). Figure 2 a shows the tensegrity hollow-rope system of the footbridge. Cables in hollowrope topology form a cable web that spans along the axis of the bridge. The web is composed of 5 pentagonal cable-networks and a lateral diamond-shape network shown in Figures $2 \mathrm{~b}$ and $2 \mathrm{~d}$ respectively. Cables on the pentagonal networks have a length of $3.66 \mathrm{~m}$ while lateral cables have a length of approximately $2.77 \mathrm{~m}$. Pentagonal cable-networks are perpendicular to the axis of the bridge forming a pentagonal straight prism (Figure 2b). Distances among consecutive pentagonal cable-networks thus define the span of each module. The lateral cable-network is made of four cables at each lateral side of the modules connecting the nodes of each pentagonal network with an intermediate node. Figure $2 \mathrm{c}$ shows cables of the lateral cable-network on a single lateral face of the bridge, while Figure $2 \mathrm{~d}$ shows the entire lateral cable-network.

Struts in hollow-rope topology are arranged in helixes along the axis of the bridge. Although all struts have the same length of $5.42 \mathrm{~m}$, two strut helixes with inversed direction are identified as shown in Figures $2 \mathrm{f}$ and $2 \mathrm{~h}$ : 5 left-hand and 5 right-hand helixes. Left-hand helixes are composed of four struts, while right-hand helixes are composed of eight. Consequently, left-hand helixes have two times larger pitch than the right-hand ones. Pitch describes a complete helix turn parallel to the axis of the helix. Figures $2 \mathrm{e}$ and $2 \mathrm{~g}$ show a single left-hand strut-helix and a single right-hand strut-helix respectively. The difference in the pitch of the helixes results directly from ring-module topology. A detailed analysis of the topology of pentagonal tensegrity-ring modules can be found in [24]. Moreover, cables on the lateral cable-network can be distinguished as right-hand or left-hand according to their helical form. Left-hand diamond cables are coplanar with left-hand strut helixes. 

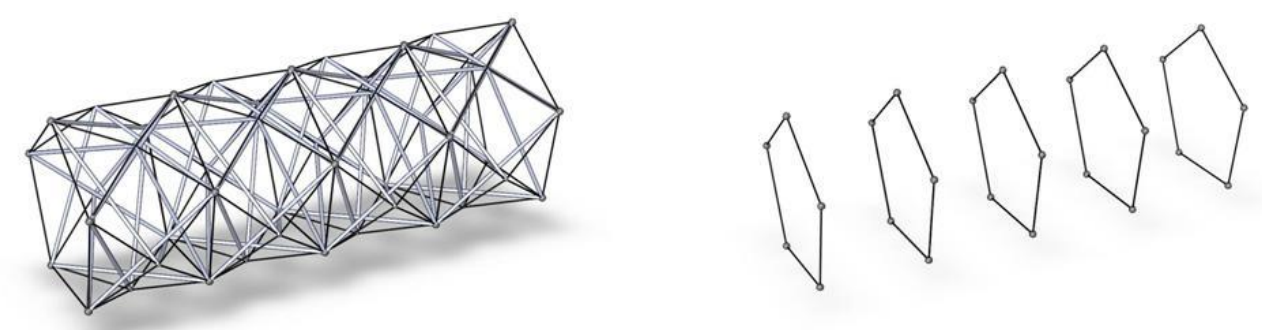

a.

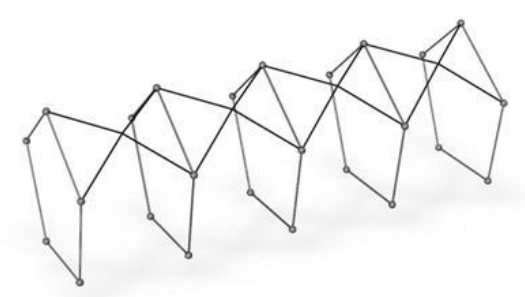

c.

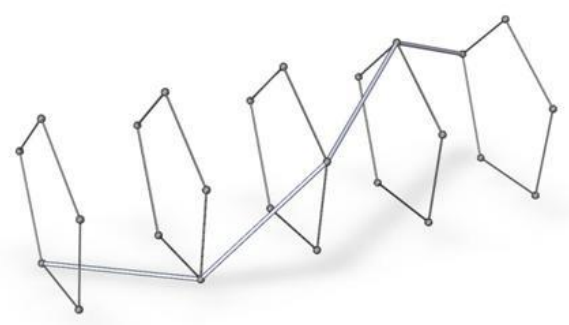

e.

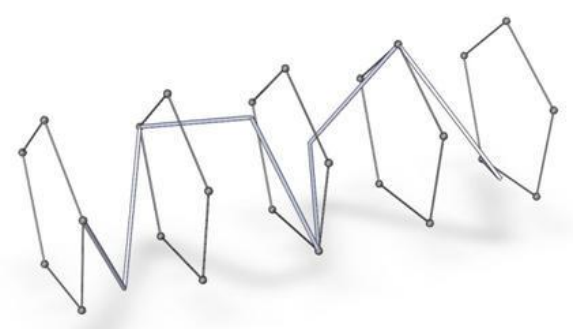

g.

Figure 2: Illustration of the tensegrity hollow-rope footbridge topology: a. the tensegrity hollow-rope system, b. the pentagonal cable networks, c. cables on a single face of the lateral cable network, d. the lateral cable network, e. struts of a left-hand strut-helix, f. the five left-hand strut-helixes, g. struts of a right-hand strut-helix and $\mathrm{h}$. the five right-hand strut-helixes.

b.

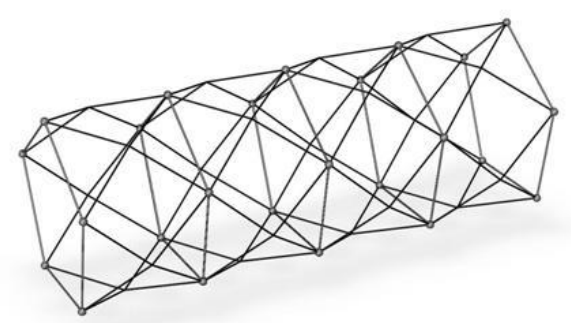

d.

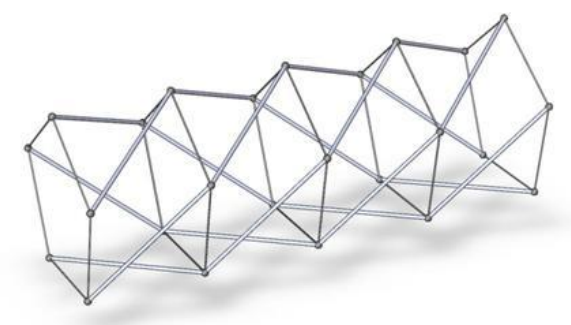

f.

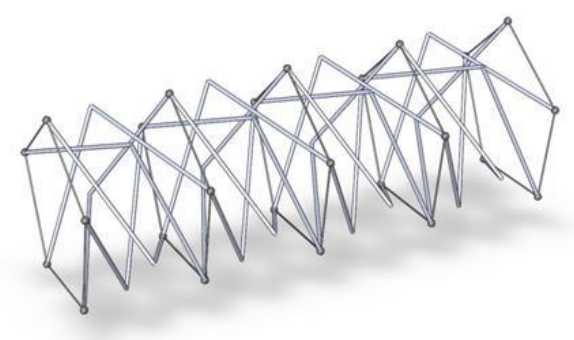

h. 


\section{Deployment}

\section{a. Contact-free motion}

Ring-module topology guarantees deployability if cable-length changes are allowed [24]. Furthermore, strut-to-strut connectivity ensures no entanglement issues during deployment. The deployment motion of a single pentagonal ring module was studied to identify the contact-free deployment-path space [31]. The deployment space remains valid for the tensegrity hollow-rope footbridge-system if all modules are assumed deploying simultaneously.

Due to its helix topology, the deployment motion of the tensegrity hollow-rope system is composed of a translation, a rotation and a dilation among the pentagonal faces of the pentagonal prism. The white space on Figure 3 describes the contact-free deployment-path space of a single tensegrity-ring module of the tensegrity footbridge based on rotation and translation of its pentagonal faces. The grey space includes configurations with strut contact. The compact configuration of the module has a maximum compact length of $0.6 \mathrm{~m}$ and a radius of approximately $4.3 \mathrm{~m}$ while the deployed configuration has a length of $4 \mathrm{~m}$ and a radius of approximately $3.1 \mathrm{~m}$. Furthermore, there is a $0.37 \mathrm{rad}\left(21^{\circ}\right)$ rotation among the pentagonal faces of the module for the compact configuration. There is no rotation of the pentagonal faces in the deployed configuration. The isometric curves in the white space represent the closest strut-to-strut distances varying from 35 to $5 \mathrm{~cm}$.

During deployment, the length of cables on pentagonal networks decreases while the length of lateral cables increases. Cables of pentagonal cable-networks vary from $4.45 \mathrm{~m}$ to $3.66 \mathrm{~m}$ during deployment, while lateral cables vary from $1.75 \mathrm{~m}$ to $2.77 \mathrm{~m}$ approximately. Consequently, deployment requires the length changes and thus actuation of both cable networks. Furthermore, boundary nodes must allow the required in-plane movement and thus are assumed blocked only along the longitudinal axis of the footbridge. The deployment motion and its corresponding cable-length changes can be explained studying the elongation of a helix.

Cable-length changes allow the module to move from one equilibrium configuration to another inside the contact-free deployment-path space. Thus, intermediate equilibrium configurations can be used to compose the deployment path of the module. Two deployment paths are highlighted on Figure 3: the path with minimum contact risk and the path with the minimum number of cable-length changes required. The path with minimum contact risk is based on the largest distances between struts. However, this path requires that all cables in the tensegrity-ring module change length. Therefore, paths requiring less cable-length changes are explored.

A deployment path allowing deployment with $33 \%$ less length-changes than the previous minimum contact-risk path was found. However, the compact length increases from $0.60 \mathrm{~m}$ to $0.80 \mathrm{~m}$ compared to the previous path. Along this path, only cables of pentagonal cablenetworks and right-hand lateral cables (Figure 4) change length during deployment. Lateral left-hand cables that are coplanar with the left-hand strut helixes do not change length but remain in tension throughout deployment. The minimum number of cable-length changes 
required for the deployment of the tensegrity-ring footbridge-system is thus 35 for each side of the bridge.

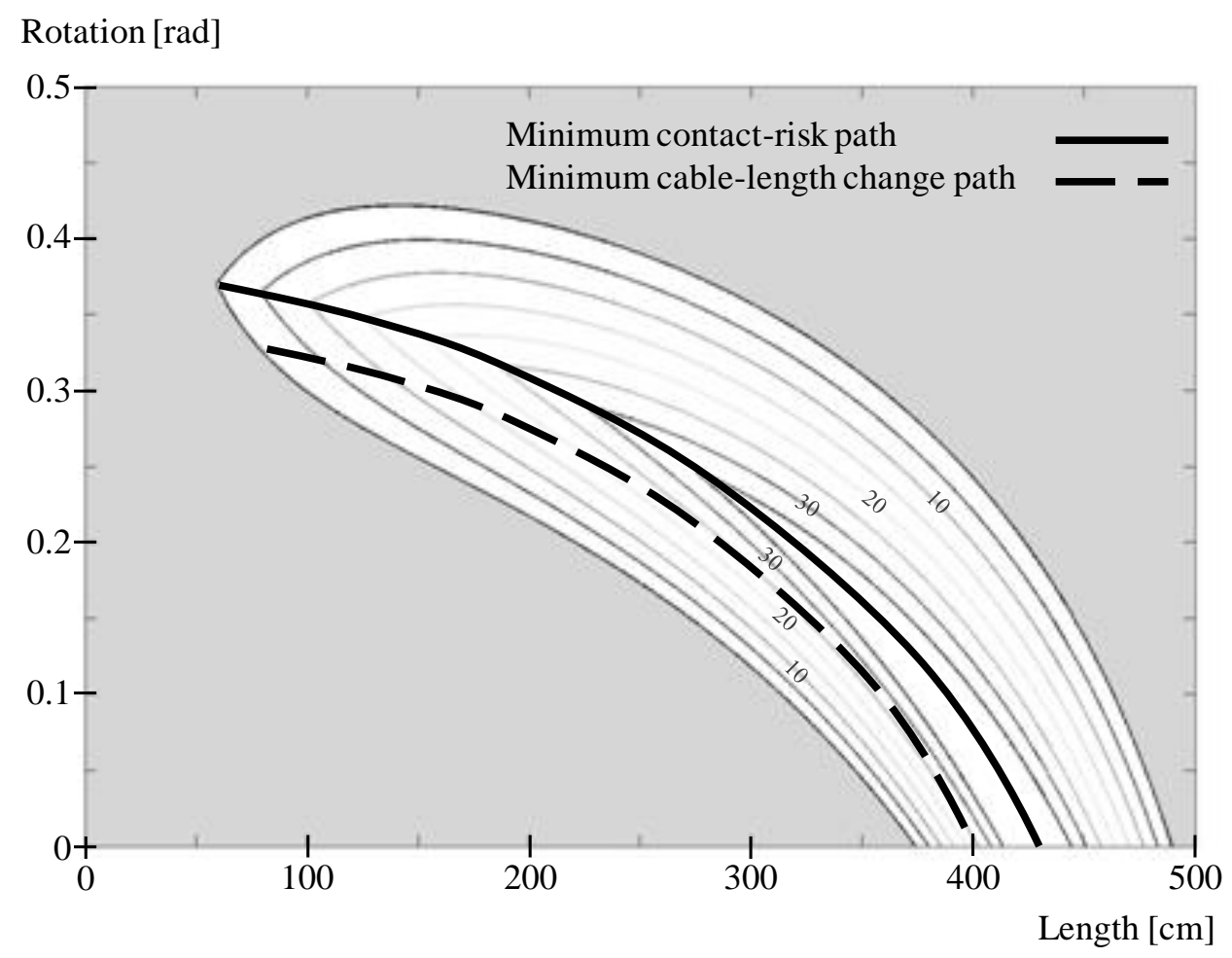

Figure 3: The strut-contact space (in grey) and the contact-free deployment-path space (in white) for a pentagonal tensegrity-ring module. Numbers 10, 20 and 30 are labels denoting contours of closest strut-to-strut distance.

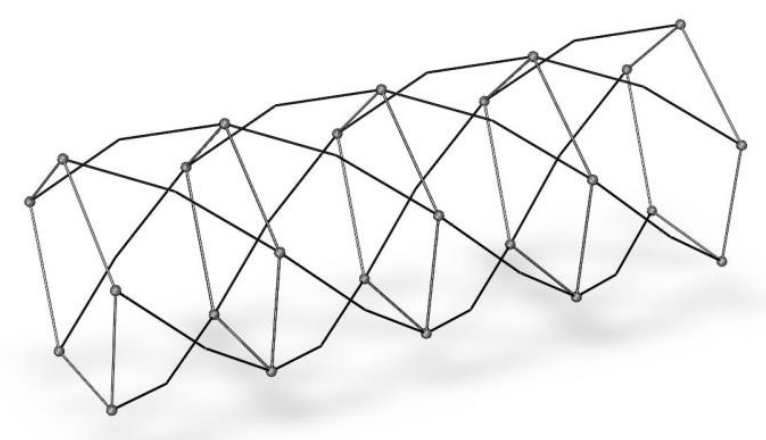

Figure 4: Topology of the length-changing cables:

pentagonal networks (Figure 2b) and right-hand lateral cables (Figure 2d).

\section{b. Actuation}

Cable-length changes and thus actuation are required for the deployment of the hollow-rope tensegrity-system. Various deployment actuation schemes can be employed. The first scheme employed is based on individual actuation: an actuator is assigned for each cable-length 
change required. Applying this scheme to the deployment-path with the minimum number of cable-length changes requires 70 actuators for the entire tensegrity system (under the assumption of a deployment conducted from both sides).

In order to reduce the number of actuators required, clustered cables are employed in the tensegrity-ring system. Clustered cables are continuous cables that run over frictionless pulleys. Although they affect tensegrity mechanics, no effect was found in the deployment motion of the pentagonal ring module [31]. For actuated clustered cables, continuous cables replace cables that sustain the identical cable-length variations. Assuming that both modules deploy simultaneously, right-hand lateral cables in the tensegrity-ring system sustain the same cable-length changes during deployment. Consequently, right-hand lateral cables (Figure 4) can be replaced by clustered cables that run over two ring modules (half of the tensegrity hollow-rope footbridge-system). Clustered cables thus connect the midspan nodes with the boundary nodes. Clustered cables could be also applied in the pentagonal cable-networks but this would result in an unstable configuration. Therefore, cables of the pentagonal networks are assumed individually actuated. The combination of clustered and unclustered actuated cables results in a total of 40 actuators for the deployable tensegrity hollow-rope footbridgesystem (42\% less actuation than the individually actuated scheme).

In order to further reduce the number of actuators, clustered cables are combined with spring elements. Spring elements allow length changes without requiring individual actuation. During deployment, the length of cables in pentagonal cable-networks decreases while the length of lateral cables increases. An inverse direction in deployment cable-length changes is thus required. Therefore, actuated cables and spring elements can be combined for deployment actuation, since spring-length changes are reactions to length changes occurring in actuated cables. If the right-hand lateral cables are assumed actuated then cables on the pentagonal networks (Figure 4) can be replaced by spring elements reducing the number of actuators required to 10 .

The use of actuated clustered cables and spring elements showed no modification in deployment motion of a single module [32]. However, tensegrity equilibrium is modified and therefore actuation-scheme aspects have to be included in the design.

\section{Design of a deployable tensegrity-structure}

Tensegrity design starts with the definition of a stable self-stressed equilibrium configuration, or form-finding. Form-finding is the primary step as not all self-stressed strut-to-cable configurations result in a stable system nor all stable systems are tensegrity systems. Formfinding has been extensively studied in recent decades [33-35]. This paper focuses on the use of the pentagonal tensegrity-ring module as a basic structural component for a deployable footbridge application. Therefore, the design task includes defining cross-sections and level of prestress for static, dynamic and deployment aspects while taking into account actuationrelated constraints.

Tensegrity structures are designed according to the civil engineering criteria of safety and serviceability. Satisfying safety and serviceability criteria leads to variations in section sizes of different tensegrity systems. Furthermore, additional criteria may be required to assure tensegrity action in all cases. Safety criteria include the overall stability of the system as well 
as member strength and stability. The overall stability of a tensegrity system is defined by form-finding. Once a stable self-equilibrated configuration is defined, self-stress may be used to modify the stiffness of the system. Increasing the level of self-stress in the system usually increases its stiffness. Therefore, self-stress has a stabilizing effect for the overall stability of the structure. However, increasing the self-stress in a tensegrity system also increases internal forces in its components. A design solution with a high self-stress state reduces the loadbearing capacity of the members as the capacity of the element remaining for loading decreases. Failure may occur if internal forces exceed buckling strength of struts or tensile strength of cables. Self-stress thus has both positive and negative effects on the tensegrity system. Consequently, both effects have to be taken into account in the design. Following previous studies [9] the effects of self-stress are distinguished using a different safety factor: 0.8 for the positive effect in overall stability and 1.2 for the negative effect in member stability. In order to guarantee the tensegrity action no cables should slack as they affect the redistribution of internal forces in the system.

Tensegrity structures are lightweight structures requiring dynamic analysis in order to avoid an excessive dynamic response. Furthermore, footbridges can be subject to vibrations due to pedestrian or wind loading. Guidelines for pedestrian induced vibrations are frequency-related defining a dangerous range of natural frequencies. Due to the peculiar geometry of tensegrity systems wind analysis should be conducted with wind-tunneling tests. Wind analysis is thus out of the scope of this paper. Finally, serviceability criteria include aspects such as functionality, comfort and appearance. They usually define displacement and natural frequency limits so that the functionality of the structure is not compromised. Load combinations and design criteria for the tensegrity hollow-rope footbridge according to Swiss construction codes SIA [36-38] are given in the Appendix.

a. Statics

In this study, static analysis of the tensegrity hollow-rope footbridge-system is performed using dynamic relaxation. Dynamic relaxation is a static method based on the equation of motion, where the static solution is seen as the resulting equilibrium state of a damped vibration [39]. Hence, Equation 1 describes a static equilibrium if all velocity-related terms are set to zero:

$$
M \dot{v}+C v+F_{i n t}=F_{e x t}
$$

Static analysis is thus transformed into a pseudo-dynamic analysis. Damping, mass and time steps in the dynamic analysis are selected so that the transient response is rapidly attenuated leaving the static solution for the applied load. In this study, kinetic damping is used for rapid convergence to the static solution. The calculation ends when an equilibrium of internal and external forces is reached; all velocity terms in Equation 1 are thus close to zero. The dynamic relaxation algorithm used in this study was modified to take into account clustered cables and spring elements [40]. A detailed presentation of the modified dynamic relaxation method can be found in $[39,40]$. 
Due to the complexity of the design task, the dynamic relaxation algorithm was combined with a genetic algorithm for structural design [30]. A simplified cost model is used as the objective function with element cross-sections and self-stress as design variables. Safety and serviceability requirements are considered as constraints in the optimization. A detailed description of the optimization is presented in [30]. The tensegrity-hollow-rope footbridge analyzed is presented in Section 2. Both struts and cables are assumed to be made of steel. The used steel grade for struts is S355, with a modulus of elasticity of $210000 \mathrm{MPa}$ and yield stress of $355 \mathrm{MPa}$. Cables are made by stainless steel with a modulus of elasticity of $120000 \mathrm{MPa}$. Load cases and design criteria are given in the Appendix. Finally, all boundary nodes are assumed blocked during service.

A design solution for the unclustered tensegrity-hollow-rope footbridge is given in Table 1 . The steel hollow tubes have a diameter of approximately $89 \mathrm{~mm}$ and a thickness of $5 \mathrm{~mm}$. Their buckling strength is thus estimated at approximately $71 \mathrm{kN}$. The steel cables have a diameter of $9 \mathrm{~mm}$ and a tensile strength of $67 \mathrm{kN}$. The prestress applied is $22.5 \%$ with respect to tensile strength of the cables and is uniformly distributed to the system. Figure 5 shows the distribution of internal forces in the unclustered tensegrity-ring footbridge-system under the Ultimate Limit State loading as well as tensile and buckling strength. Maximum values of compression and tension are observed in struts of left-hand helixes and right-hand lateral cables respectively. There are no slack cables under service loading but some struts sustain tension. The average midspan displacement under service is less than $1.0 \mathrm{~cm}$ satisfying the displacement criterion set at $2.7 \mathrm{~cm}$ for the $16 \mathrm{~m}$ span (Appendix).

Table 1: Design solution according to static requirements for:

a) unclustered, b) clustered, c) clustered-spring tensegrity-footbridge system

\begin{tabular}{|c|c|c|c|c|c|c|c|c|c|c|c|c|c|c|c|c|}
\hline \multirow[b]{2}{*}{ System } & \multirow[t]{2}{*}{$\begin{array}{c}\text { Length } \\
{[\mathrm{m}]}\end{array}$} & \multicolumn{3}{|c|}{$\begin{array}{c}\text { Diameter } \\
{[\mathrm{mm}]}\end{array}$} & \multicolumn{3}{|c|}{$\begin{array}{c}\text { Thickness } \\
\text { [mm] }\end{array}$} & \multicolumn{3}{|c|}{$\begin{array}{c}\text { Element } \\
\text { strength } \\
{[\mathrm{kN}]}\end{array}$} & \multicolumn{3}{|c|}{$\begin{array}{l}\text { Self-stress } \\
\text { [\% element } \\
\text { strength] }\end{array}$} & \multicolumn{3}{|c|}{$\begin{array}{c}\text { Max force in } \\
\text { service } \\
{[\mathrm{kN}]}\end{array}$} \\
\hline & & a) & b) & c) & a) & b) & c) & a) & b) & c) & a) & b) & c) & a) & b) & c) \\
\hline Struts & 5.42 & 89 & 89 & 101.6 & 5 & 6.3 & 8 & 71 & 86 & 157 & - & - & - & 65 & 79 & 136 \\
\hline $\begin{array}{l}\text { Cables on } \\
\text { pentagonal } \\
\text { networks }\end{array}$ & $3.66 *$ & 9 & 11 & $*$ & - & - & - & 67 & 101 & $*$ & 22.5 & 17.5 & $*$ & 38 & 56 & - \\
\hline $\begin{array}{l}\text { Cables on } \\
\text { lateral } \\
\text { network }\end{array}$ & 2.77 & 9 & 11 & 14 & - & - & - & 67 & 101 & 154 & 22.5 & 17.5 & 17.5 & 47 & 75 & 90 \\
\hline
\end{tabular}

* Spring elements: initial length of $3.50 \mathrm{~m}$ and stiffness equals to $10 \%$ of cable stiffness 


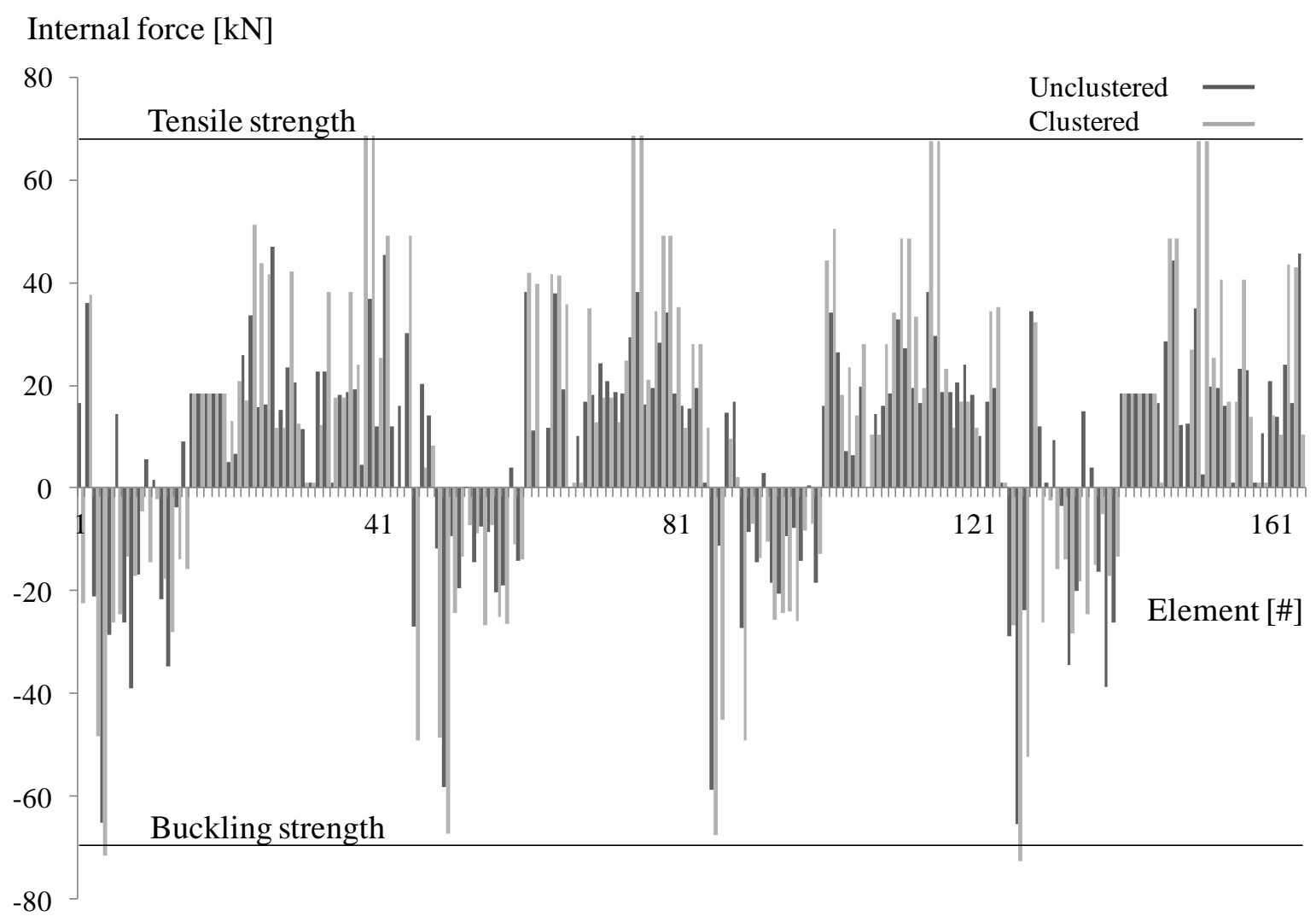

Figure 5: Internal force distribution in the unclustered and clustered tensegrity-footbridge system under ULS loading

Clustered cables modify tensegrity mechanics. Consequently employing clustered cables in the tensegrity hollow-rope footbridge-system may influence the design solution In this configuration, clustered cables are employed in the right-hand cables of the diamond cablenetwork. Figure 5 shows that the distribution of internal forces in the clustered tensegrity system is different compared with the unclustered system. Struts and cables in the clustered system sustain higher internal forces compared with the unclustered system reaching buckling and tensile strength of struts and cables respectively under service. Furthermore, maximum tensile forces are not observed in the same elements. Thus, the unclustered design solution is not valid for the clustered configuration. Furthermore, although the two configurations are composed of the same elements, the stiffness of the clustered system is lower compared with the unclustered system. This is due to a lower number of kinematic constraints. Additionally, average vertical displacement at midspan is increased to $3.4 \mathrm{~cm}$ thus violating the serviceability criterion. A new design solution is found for the clustered configuration and is presented on Table 1b). The clustered design solution has elements with larger cross-sections and lower self-stress.

Spring elements can also be employed in the tensegrity-hollow-rope bridge-system. The main advantage of employing spring elements is that they can absorb displacements in the system without requiring actuation. Spring reaction depends on spring stiffness and initial length. Spring characteristics can be defined so that the distribution of internal forces in the tensegrity system remains similar to its corresponding cable configuration. However, the stiffness of the tensegrity system with spring elements decreases thus requiring a new design solution. An 
initial spring length of $3.50 \mathrm{~m}$ is assumed in this study to study the effect of spring stiffness in the tensegrity system. If spring elements replace cables of the pentagonal networks for the clustered design solution of Table 1b) then there is no spring stiffness for this value of spring length that satisfies both element strength and vertical displacements. Consequently, a new design solution for the clustered-spring configuration is found (Table 1c) meeting both static requirement of element strength and displacements. In this design solution, spring stiffness corresponds to approximately $10 \%$ of the cable stiffness. The clustered-spring design solution has elements with larger cross-sections compared with the cable design solutions.

\section{b. Dynamics}

The linearized dynamic model is a good approximation of the nonlinear behavior of tensegrity systems around equilibrium configurations [41]. Therefore, the dynamic analysis of the tensegrity hollow-rope footbridge is conducted using the linearized equation of motion given in Equation 2 where $M$ is the mass matrix, $K_{T}$ is the tangent stiffness matrix, $u$ and $\ddot{u}$ are respectively vectors of nodal displacement and acceleration and $F$ is the applied load vector:

$$
[M]\{\ddot{u}\}+\left[K_{T}\right]\{u\}=\{F\}
$$

Eigen-frequency analysis based on small harmonic motion is conducted to determine the natural frequencies and corresponding mode shapes of the system. The dynamic analysis is conducted for the tensegrity hollow-rope design-solutions resulting from the static analysis (Table 1) with an additional mass for the footbridge deck. The mass of pedestrians is not taken into account in this study.

Table 2: Natural frequencies of the tensegrity-footbridge system configurations

\begin{tabular}{|c|c|c|c|c|c|}
\hline \multirow{2}{*}{$\begin{array}{l}\text { Tensegrity system } \\
\text { Unclustered } \\
\text { (Design solution of Table 1a) }\end{array}$} & \multicolumn{5}{|c|}{ Natural frequencies $[\mathrm{Hz}]$} \\
\hline & 4.80 & 5.50 & 7.20 & 9.20 & 10.00 \\
\hline $\begin{array}{l}\text { Clustered } \\
\text { (Design solution of Table 1b) }\end{array}$ & 3.00 & 3.20 & 4.20 & 4.60 & 5.00 \\
\hline $\begin{array}{l}\text { Clustered-spring } \\
\text { (Design solution of Table 1c) }\end{array}$ & 3.35 & 3.60 & 4.60 & 4.85 & 5.30 \\
\hline
\end{tabular}

Results of the eigen-frequency analysis for the design solutions resulting from the static analysis are presented in Table 2. The first and second modes of the tensegrity hollow-rope footbridge correspond to vertical and lateral bending modes respectively. All modules oscillate in the same direction along the span of the footbridge. The third mode is a torsion mode. The fourth and fifth modes also correspond to bending modes but with each half of the footbridge oscillating in an inverse direction.

The unclustered design solution (Table 1a) has the highest natural frequencies compared with the other configurations as shown in Table 2. The first natural frequency of the unclustered 
tensegrity hollow-rope footbridge system is found at approximately $4.80 \mathrm{~Hz}$ which is beyond the range of frequencies to be avoided for footbridges according to Swiss construction codes SIA (frequencies to be avoided in the vertical direction: 1.6 to $4.5 \mathrm{~Hz}$ ). Consequently, the unclustered design solution meets both static and dynamic requirements. The stiffness of the unclustered tensegrity system is due to self-stress and the absence of infinitesimal mechanisms. Therefore, pre-stressing the tensegrity system beyond a certain value will not affect its stiffness or its dynamic behavior.

The dynamic behavior of the tensegrity system is modified when clustered cables are employed. Clustered cables decrease significantly the natural frequencies of the tensegrity hollow-rope system due to a lower number of kinematic constraints. Table 2 shows the natural frequencies of the clustered design solution resulting from the statics analysis (Table 1b). The first natural frequency of the clustered tensegrity hollow-rope footbridge-system is estimated at approximately $3.00 \mathrm{~Hz}$ which is within the range of frequencies that must be avoided according to design codes. Additionally, there is a risk of combined modes as the frequencies are closely-spaced. To avoid dynamic issues with clustered cables, dynamics are integrated in the design as an additional design constraint. If not, design measures have to be taken such as the addition of mass dampers. A new design solution that verifies both static and dynamic requirements for the clustered configuration is given in Table $3 \mathrm{~b}$. This solution has a first natural frequency in the vertical direction of approximately $4.75 \mathrm{~Hz}$ satisfying thus dynamic and static requirements.

Table 3: Design solution according to static and dynamic requirements for:

a) unclustered, b) clustered, c) clustered-spring tensegrity-footbridge system

\begin{tabular}{|c|c|c|c|c|c|c|c|c|c|c|c|c|c|c|c|c|}
\hline \multirow[b]{2}{*}{ System } & \multirow[t]{2}{*}{$\begin{array}{c}\text { Length } \\
\text { [m] }\end{array}$} & \multicolumn{3}{|c|}{$\begin{array}{c}\text { Diameter } \\
{[\mathrm{mm}]}\end{array}$} & \multicolumn{3}{|c|}{$\begin{array}{c}\text { Thickness } \\
{[\mathrm{mm}]}\end{array}$} & \multicolumn{3}{|c|}{$\begin{array}{c}\text { Element } \\
\text { strength } \\
{[\mathrm{kN}]}\end{array}$} & \multicolumn{3}{|c|}{$\begin{array}{l}\text { Self-stress } \\
\text { [\% element } \\
\text { strength] }\end{array}$} & \multicolumn{3}{|c|}{$\begin{array}{c}\text { Max force in } \\
\text { service } \\
{[\mathrm{kN}]}\end{array}$} \\
\hline & & a) & b) & c) & a) & b) & c) & a) & b) & c) & a) & b) & c) & a) & b) & c) \\
\hline Struts & 5.42 & 89 & 114.3 & 114.3 & 5 & 4.0 & 5 & 71 & 124 & 151 & - & - & - & 65 & 91.5 & 128 \\
\hline $\begin{array}{l}\text { Cables on } \\
\text { pentagonal } \\
\text { networks }\end{array}$ & 3.66 & 9 & 18 & $*$ & - & - & - & 67 & 254 & $*$ & 22.5 & 15 & $*$ & 38 & 65.8 & - \\
\hline $\begin{array}{l}\text { Cables on } \\
\text { lateral } \\
\text { network }\end{array}$ & 2.77 & 9 & 18 & 20 & - & - & - & 67 & 254 & 314 & 22.5 & 15 & 15 & 47 & 93.6 & 95 \\
\hline
\end{tabular}

* Spring elements: initial length of $3.50 \mathrm{~m}$ and stiffness equals to $10 \%$ of cable stiffness

Table 2 shows the natural frequencies for the clustered-spring design solution resulting from the static analysis as shown in Table 1c. The first natural frequency for this configuration of the tensegrity hollow-rope footbridge-system is found at approximately $3.35 \mathrm{~Hz}$ thus not meeting dynamic requirements. If spring elements were not employed in this design solution of the tensegrity system then the first natural frequency would be around $3.60 \mathrm{~Hz}$. Consequently, employing spring elements in the tensegrity system further decreases the 
natural frequencies of the system. In order to meet both static and dynamic criteria, the design solution is modified by taking into account dynamic requirements as an additional design constraint. A new design solution that verifies both static and dynamic requirements for the clustered-spring configuration is given in Table $3 \mathrm{c}$. This solution has a first natural frequency in the vertical direction of approximately $4.80 \mathrm{~Hz}$ satisfying thus dynamic and static requirements.

\section{Deployment in design}

Deployment is usually not a critical case for the design of deployment structures since most of them explore SDOF mechanisms for changing shape and the only loading applied is dead load. Tensegrity systems are MDOF systems that need actuation for deployment. Actuation schemes influence tensegrity mechanics as shown in Section 4. Deployment may further influence the design solutions due to the large length changes required. Furthermore, since deployment requires actuation, actuation-related constraints should be taken into account in the design. The controllability of the system depends on the number of actuators integrated in it. However, increasing the number of actuators increases the complexity of the design and control of the structure. The complexity of the control increases exponentially with the number of actuators. Constraints in the volume, weight and natural frequencies of actuators may also become critical. Finally, integrating a large number of actuators may increase cost significantly.

In this study, deployment analysis is performed using an algorithm that explores the modified dynamic relaxation algorithm that was modified to include cable continuity. Deployment is simulated through a series of static analyses under two main assumptions: quasi-static control and no-friction. Deployment analysis is conducted for two interconnected pentagonal ringmodules (half-footbridge) since deployment is assumed from both sides. Furthermore, the modules are assumed to deploy simultaneously. In order to follow the deployment motion, boundary nodes are assumed to allow the required in-plane movements while longitudinal movements remain blocked. Furthermore, no service loading is considered during deployment; deployment analysis is conducted only with dead load.

The deployment analysis algorithm integrates actuation schemes in the modified dynamic relaxation algorithm. Module topology, element characteristics and actuated elements (individually actuated cables, clustered actuated cables or spring elements) are inputs for the analysis. Cable-actuation deployment with unclustered or clustered actuated cables is based on the creation of a series of finite mechanisms allowing the module to change shape. Since tensegrity modules are stable systems, cable actuation is used to create and stabilize a finite mechanism. Consequently, simultaneous action of mechanism creation and stabilization preserves the equilibrium of the tensegrity system during deployment and thus the stiffness of the system. Actuation is implemented as an increase or decrease of the length of actuated cables. For unfolding, right-hand lateral cables of the tensegrity hollow-rope footbridgesystem are actuated first by increasing their length. Then the lengths of actuated cables in the pentagonal networks are decreased to stabilize the mechanism created by the actuation of lateral cables. The actuation sequence is inversed for folding. After each actuation, a new equilibrium configuration with a new system length is found. Thus, parallel actions of lateral 
cables along with cables in the pentagonal networks (Figure 4) maintain the structure close to equilibrium throughout deployment. Consequently, deployment is composed of a series of equilibrium configurations with different system lengths.

The number of intermediate equilibrium configurations considered in the deployment analysis is defined by the actuation step. Large actuation steps may result in unstable configurations, while small actuation steps are computationally expensive. If the deployment-actuation scheme includes spring elements, then no actuation is required for these elements. Spring elements adapt their length to shape changes defined by actuated cables. However, spring characteristics (spring stiffness and free-length) may considerably affect the equilibrium. For the deployment analysis of the tensegrity hollow-rope footbridge-system, the same actuation step is applied to all actuated cables. Individual actuation steps can be applied to each actuator if required thus leading to a better control of the shape of the structure. If the configuration includes spring elements, then shape control is also affected by spring characteristics. Spring characteristics may be individually optimized according to the shape of the structure.

Constraints such as strut contact, maximum values of internal forces or geometrical relationships can be integrated to control intermediate equilibrium configurations thus avoiding problematic configurations. The repeated sequence "actuation - analysis and equilibrium - constraints" leads to unfolding or folding the system. Figure 6 illustrates the main steps of the deployment-analysis algorithm. In this study, deployment is studied by analyzing the folding phase as the reference configuration for the design is the deployed configuration. Folding and unfolding are assumed as identical phases.

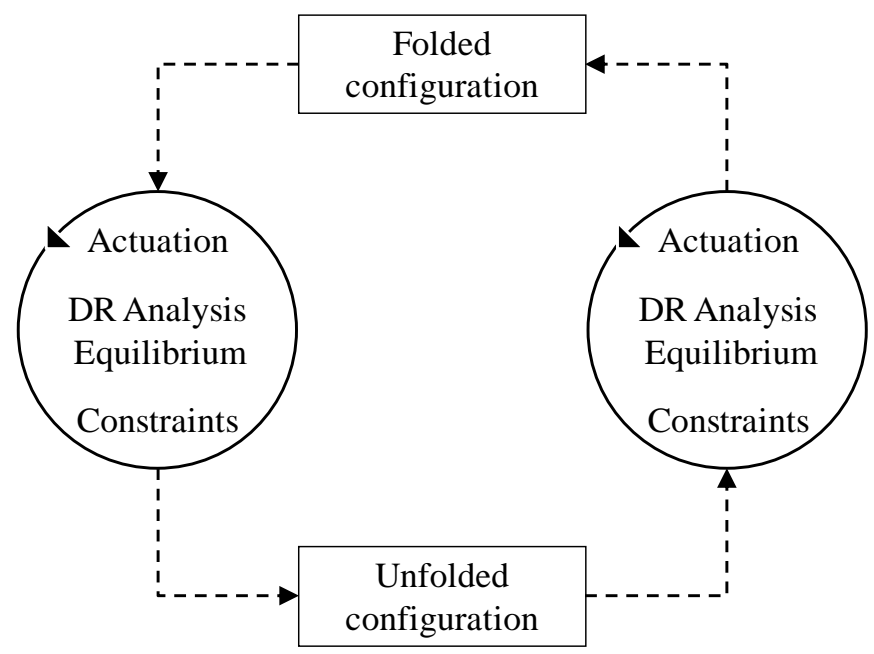

Figure 6: Illustration of the deployment analysis using the Dynamic Relaxation (DR) method

Cable-actuation deployment with unclustered cables requires 70 actuators (an actuator per cable), while employing clustered actuated cables reduces the number of actuators required to 40. Each clustered cable is assumed to be controlled by a single actuator. Since clustered right-hand cables run through the boundary nodes, actuators can be placed on the supports to reduce design constraints related to actuators. However, the total number of actuators for both configurations remains large considering the complexity in the design and control as well as 
cost. Furthermore, due to the complexity in the control task adding shape-related criteria such as parallelism among the faces of the modules results in a better deployment.

Internal forces in the tensegrity-hollow-rope system during deployment are due to dead load and self-stress. Self-stress is regulated by deployment actuation as it defines intermediate equilibrium configurations. However, actuation may lead to stable configurations with high self-stress. Therefore, self-stress is regulated to avoid high internal forces during deployment. Figure 7 and 8 show maximal internal forces during folding for the unclustered and clustered actuated design solutions respectively as derived from Section 4 (design solutions a) and b) presented in Table 3). In both cases, internal forces remain approximately at the same level during folding. Furthermore, they are lower compared with the tensile and buckling strength of the design solutions resulting from structural design. The deployment analysis is conducted with only dead load and the same actuation step of approximately $2 \mathrm{~mm}$ applied to all actuated cables. The unclustered actuated configuration folds completely reaching a compact system length of $1.6 \mathrm{~m}$ while the folding of the clustered actuated configuration stops at approximately a system length of $3 \mathrm{~m}$. This is due to a better controllability of the shape compared with the clustered actuated configuration.

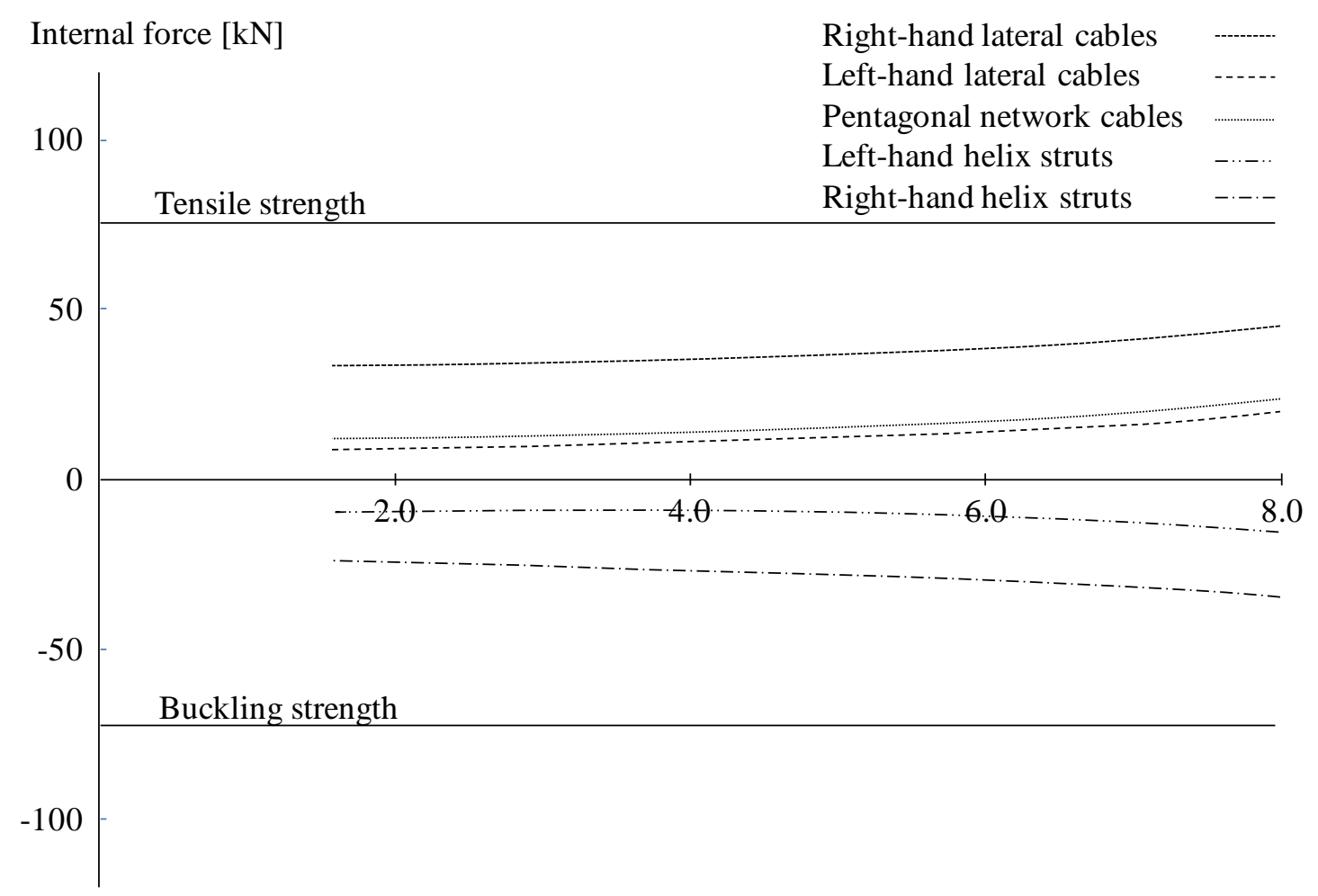

Figure 7: Maximal internal forces in the tensegrity footbridge-system during folding for the design solution with actuated unclustered cables (design solution presented in Table 3a) 


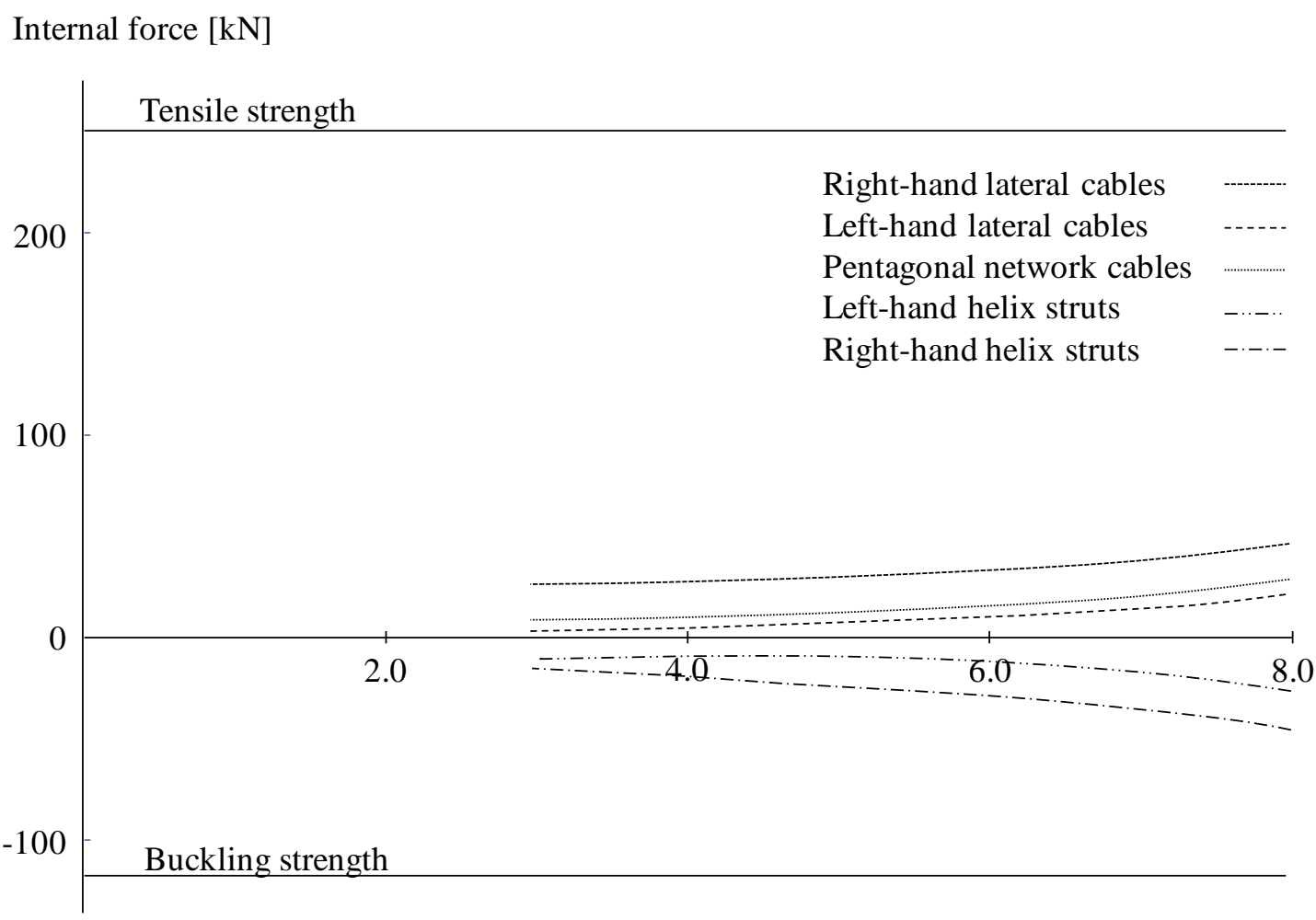

Figure 8: Maximal internal forces in the tensegrity footbridge-system during folding for the design solution with actuated clustered cables (design solution presented in Table $3 b$ )

Employing spring elements and clustered actuated cables reduces the number of actuators required to 5 per side of the footbridge. Spring-length changes are controlled by the actuated clustered cables. However, the controllability of the system is significantly affected by spring characteristics since actions on cables and springs are coupled. Then again, since clustered cables go through the boundary nodes deployment can be entirely controlled by actuators placed on the supports thus eliminating actuation-related design-constraints. However, in this configuration actuators would have to overcome spring-reaction. If a single actuation step is assumed for all actuated clustered cables then the number of actuators required for the deployment of the tensegrity hollow-rope footbridge can be further reduced to 2 since all cables can be connected to the same actuation device.

Spring elements do not require individual actuation but they affect the internal forces especially if large length changes occur. For the tensegrity hollow-rope footbridge-system with actuated clustered cables and spring elements, folding is controlled by cable action: decreasing the length of right-hand lateral cables elongates spring elements (replacing cables in pentagonal networks) initiating the rotation of the system and thus folding. Figure 9 shows the maximal internal forces in the tensegrity footbridge-system during folding for the design solution of the clustered-spring configuration presented in Table 3c. Contrary to cableactuation deployment, internal forces increase with folding since spring elements elongate as the system length decreases. Spring characteristics are determined to meet static and dynamic criteria. Spring elongation thus leads to rapidly increasing internal forces with folding that rise above element strength for the design solution of Table 3c. Consequently, deployment becomes a critical design case for the clustered-spring tensegrity configuration. 


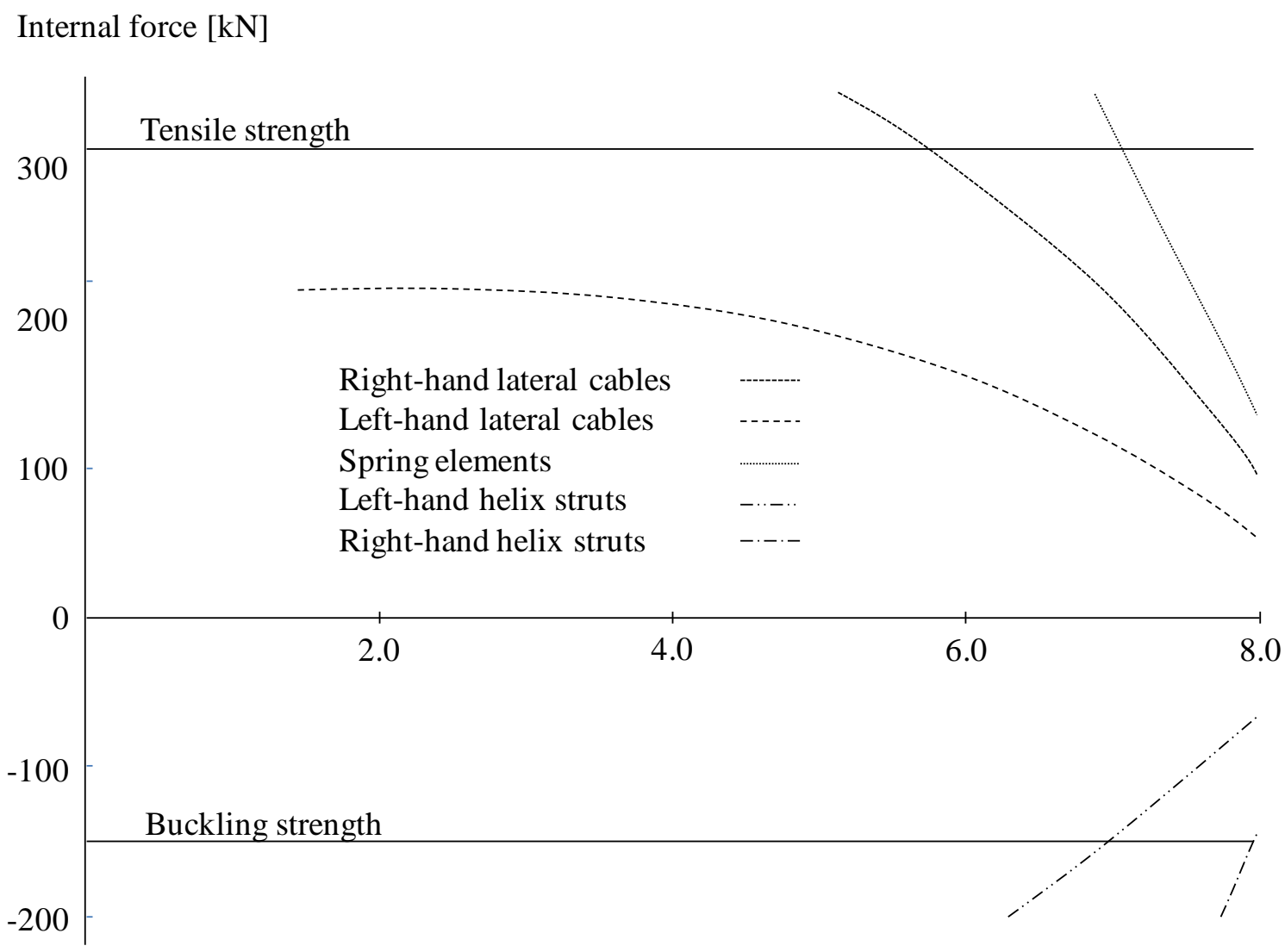

Figure 9: Maximal internal forces in the tensegrity footbridge-system during folding exceeding element strength of the clustered-spring configuration (design solution presented in Table 3c)

A solution that meets all requirements (static, dynamic and deployment) for this value of spring stiffness is found and is presented in Table 4. The first natural frequency of design solution of Table 4 is found at $8 \mathrm{~Hz}$ and vertical displacements under service are approximately of $1 \mathrm{~cm}$. Nevertheless, this solution may not be considered as element sizing is significantly increased beyond acceptable values for such span.

Table 4: Design solution for the clustered-spring tensegrity footbridge according to static, dynamic and deployment requirements.

\begin{tabular}{|c|c|c|c|c|c|c|}
\hline & $\begin{array}{l}\text { Length } \\
\text { [m] }\end{array}$ & $\begin{array}{c}\text { Diameter } \\
{[\mathrm{mm}]}\end{array}$ & $\begin{array}{c}\text { Thickness } \\
\text { [mm] }\end{array}$ & $\begin{array}{c}\text { Element } \\
\text { strength } \\
{[\mathrm{kN}]}\end{array}$ & $\begin{array}{l}\text { Self-stress } \\
\text { [\% element } \\
\text { strength] }\end{array}$ & $\begin{array}{c}\text { Max force in } \\
\text { service } \\
{[\mathrm{kN}]}\end{array}$ \\
\hline Struts & 5.42 & 193.7 & 10 & 1170 & - & 79 \\
\hline $\begin{array}{l}\text { Cables on } \\
\text { lateral } \\
\text { network }\end{array}$ & 2.77 & 40 & - & 1200 & 17.5 & 375 \\
\hline
\end{tabular}

* Spring elements: initial length of $3.50 \mathrm{~m}$ and stiffness equals to $10 \%$ of cable stiffness 
Deployment is found to be feasible with lower values of spring stiffness. However, lower values of spring stiffness affect the behavior of the tensegrity system in relation with the static and dynamic requirements. Figure 10 shows the maximal internal forces in the tensegrity hollow-rope footbridge-system during folding for the cluster-spring configuration of Table $3 \mathrm{c}$ with $10 \%$ of spring stiffness. For this configuration, folding is successfully conducted with a folded length of $1.6 \mathrm{~m}$ and the dangerous frequency range is avoided with a first natural frequency expected at approximately $4.7 \mathrm{~Hz}$. Vertical displacements under service loading are estimated at approximately $4 \mathrm{~cm}$ thus exceeding the serviceability requirement of $2.7 \mathrm{~cm}$. However, due to significant improvements in actuation, deployment excessive displacements beyond the defined serviceability criteria may be accepted. Consequently, a design solution with lower element sizing that meets all requirements is feasible if only the displacementconstraint is relaxed.

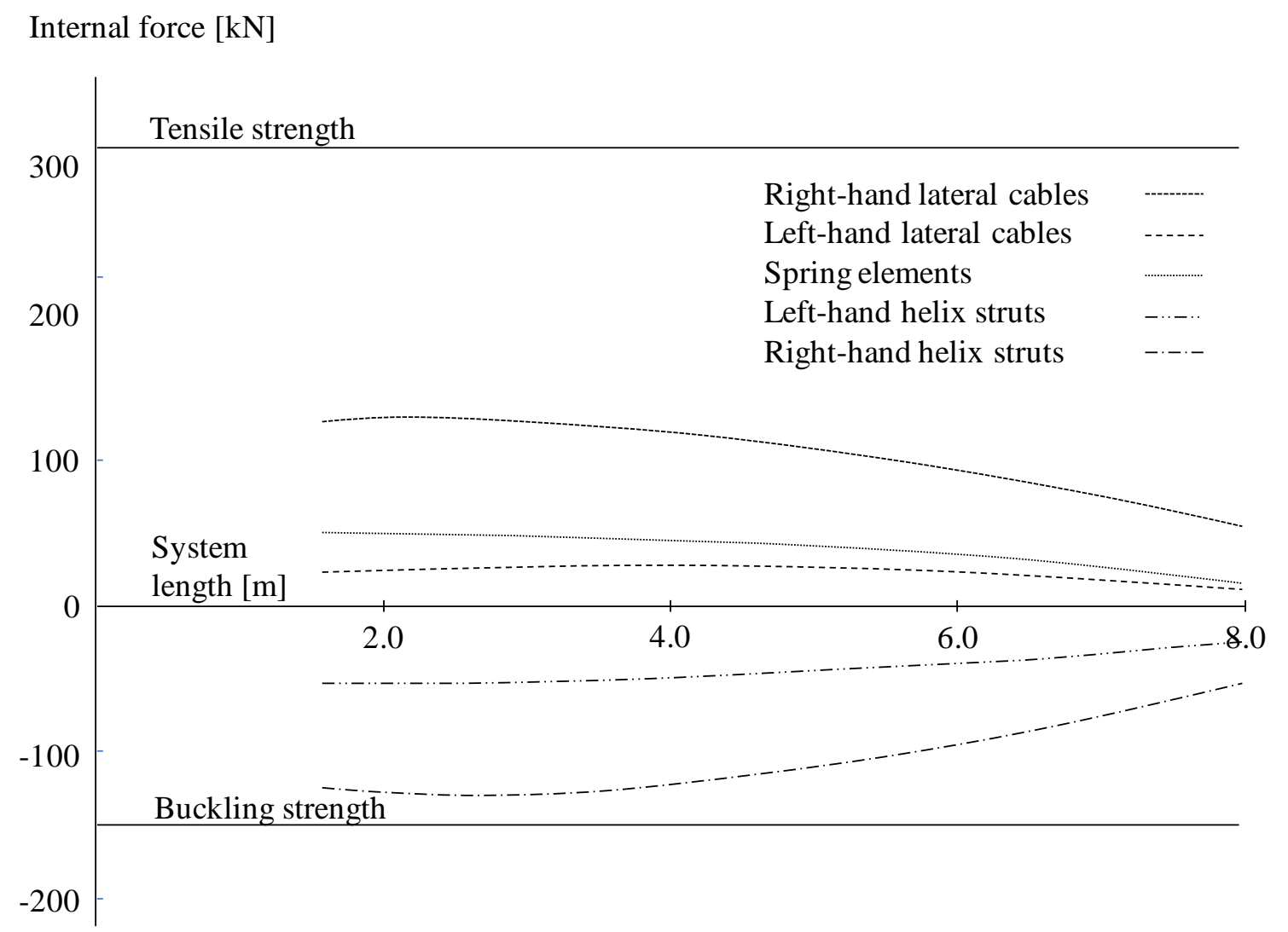

Figure 10: Maximal internal forces in the tensegrity footbridge-system during folding for a clusterspring configuration assuming a relaxed displacement constraint

\section{Conclusions}

The design of a deployable tensegrity hollow-rope footbridge is carried out including static, dynamic and deployment as well as actuation-related aspects. The conclusions of this study are as follows: 
- If unclustered actuated cables are employed in the tensegrity-hollow-rope footbridge system, deployment is not a critical design case. The design is governed by static requirements. Dynamic requirements are also met due to self-stress and the absence of infinitesimal mechanisms in the tensegrity system. However, due to a large number of actuators required, actuator related design constraints may become critical for the design.

- If clustered actuated cables are employed in the tensegrity-hollow-rope footbridge system, deployment is not a critical design case. However, the design solution found for the unclustered configuration is not valid for the clustered configuration as internal forces and displacements of the clustered configuration under service are higher. Furthermore, the dynamic behavior of the system becomes critical for the clustered design solutions. A design solution that meets both static and dynamic criteria thus has to be found. Finally, actuator related design constraints are reduced but remain active.

- Deployment is the critical design case when spring elements are integrated in the actuation scheme of the tensegrity footbridge. If spring characteristics are defined to meet all static and dynamic requirements, then element sizing increases significantly. If spring characteristics are defined according to safety criteria for deployment and service as well as for dynamic requirements, excessive vertical displacements may occur under service. However, employing spring elements decreases significantly the number of actuators and eliminates actuator-related constraints.

These results underline the importance of including deployment (or other shape changes that require large element-length changes) and actuation schemes along with traditional design cases when designing deployable tensegrity structures.

\section{Acknowledgements}

Authors would like to thank the Swiss National Science Foundation for supporting this work through contract number 200020_131839. They are also grateful to Bernd Domer for discussions. 
8. Appendix: Design loading and criteria

Table 5: Design load-combinations

\begin{tabular}{|c|c|c|c|c|c|c|}
\hline \multirow{2}{*}{ State } & \multicolumn{6}{|c|}{ Load combination } \\
\hline & Factor & Dead load & Factor & Live load & Factor & Self-stress \\
\hline $\begin{array}{l}\text { Ultimate } \\
\text { Limit } \\
\text { State }\end{array}$ & 1.35 & $78.5 \mathrm{kN} / \mathrm{m}^{3}$ & 1.5 & $\begin{array}{l}\text { Vertically: } \\
4 \mathrm{kN} / \mathrm{m}^{2} \text { and } 10 \mathrm{kN} \\
\text { Horizontally: } \\
10 \% \text { of vertical } \\
\text { loading }\end{array}$ & $\begin{array}{l}\text { Globally: } \\
0.80 \\
\text { Locally: } \\
1.20\end{array}$ & $\begin{array}{l}\text { Max. value: } \\
25 \% \text { of the } \\
\text { tensile } \\
\text { strength }\end{array}$ \\
\hline $\begin{array}{l}\text { Serviceability } \\
\text { Limit } \\
\text { State }\end{array}$ & 1.00 & $78.5 \mathrm{kN} / \mathrm{m}^{3}$ & 0.4 & $\begin{array}{l}\text { Vertically: } \\
4 \mathrm{kN} / \mathrm{m}^{2} \text { and } 10 \mathrm{kN} \\
\text { Horizontally: } \\
10 \% \text { of the vertical } \\
\text { load }\end{array}$ & 1.00 & $\begin{array}{l}\text { Max. value: } \\
25 \% \text { of the } \\
\text { tensile } \\
\text { strength }\end{array}$ \\
\hline
\end{tabular}

Table 6: Design criteria

\begin{tabular}{|c|c|c|c|c|}
\hline \multirow[b]{2}{*}{ State } & \multicolumn{4}{|c|}{ Criteria } \\
\hline & Tensile strength & Buckling strength & $\begin{array}{l}\text { Midspan } \\
\text { displacement }\end{array}$ & Natural frequencies \\
\hline $\begin{array}{l}\text { Ultimate Limit } \\
\text { State }\end{array}$ & $\begin{array}{c}\mathrm{N}_{\mathrm{d}}<\mathrm{N}_{\mathrm{Rd}} \text { where } \\
N_{R d}=\frac{f_{y} A}{1.05}\end{array}$ & $\begin{array}{c}\mathrm{N}_{\mathrm{d}}<\mathrm{N}_{\mathrm{Rd}} \text { where } \\
N_{R d}=\frac{\chi_{k} f_{y} A}{1.05}\end{array}$ & {$[-]$} & $\begin{array}{l}\text { Vertically: } \\
\mathrm{f}<1.6 \mathrm{~Hz} \\
\text { and }\end{array}$ \\
\hline $\begin{array}{l}\text { Serviceability } \\
\text { Limit } \\
\text { State }\end{array}$ & $\mathrm{N}_{\mathrm{d}}<\mathrm{N}_{\mathrm{Rd}}$ & $\mathrm{N}_{\mathrm{d}}<\mathrm{N}_{\mathrm{Rd}}$ & Span / 600 & $\begin{array}{l}\text { Transversally: } \\
\mathrm{f}>1.3 \mathrm{~Hz} \\
\text { Longitudinally: } \\
\mathrm{f}>2.5 \mathrm{~Hz}\end{array}$ \\
\hline
\end{tabular}


9. References

1. Snelson, K., Continuous tension, discontinuous compression structures. 1965: U.S Patent No. 3,169,611.

2. Motro, R., Tenségrité. 2005: Hermes Science.

3. Skelton, R., et al., An Introduction to the Mechanics of Tensegrity Structures, in The Mechanical Systems Design Handbook. 2009, CRC Press.

4. $\quad$ Skelton, R.E. and M.C. de Oliveira, Tensegrity systems. 2009: Springer.

5. Paronesso, A. The 2002 World Cycling Center Arena Aigle, Switzerland. in International IASS Symposium on "Lightweight Structures in Civil Engineering". 2002. Warsaw, Poland.

6. Schlaich, M., The Messeturm in Rostock- A Tensegrity Tower. Journal of the International Association for Shell and Spatial Structures (J. IASS), 2004. Vol. 45 (No. 2).

7. Gómez-Jáuregui, V., Tensegrity Structures and their Application to Architecture. 2010: Servicio de Publicaciones de la Universidad de Cantabria.

8. Kawaguchi, K., S. Ohya, and S. Vormus, Long-Term Monitoring of White Rhino, Building with Tensegrity Skeletons, in 5th Annual Symposium of IABSE / 52nd Annual Symposium of IASS / 6th International Conference on Space Structures. 2011: London, September 2011.

9. Quirant, J., M.N. Kazi-Aoual, and R. Motro, Designing tensegrity systems: the case of a double layer grid. Engineering Structures, 2003. 25(9): p. 1121-1130.

10. Rhode-Barbarigos, L., et al., Design of tensegrity structures using parametric analysis and stochastic search. Engineering with Computers. 2010. 26(2): p. 193-203.

11. Koohestani, K., Form-finding of tensegrity structures via genetic algorithm. International Journal of Solids and Structures. 2011. 49(5): p. 739-747.

12. Bouderbala, M. and R. Motro, Folding tensegrity systems, in IUTAM-IASS Symposium on Deployable Structures: Theory and Applications. 1998: Cambridge, UK.

13. Tibert, A.G., Pellegrino, S. Deployable Tensegrity Masts. in 44th AIAA/ASME/ASCE/AHS/ASC Structures, Structural Dynamics, and Material Conference and Exhibit. 2003. Norfolk, VA.

14. Fest, E., K. Shea, and I.F.C. Smith, Active Tensegrity Structure. Journal of Structural Engineering, 2004. 130(10): p. 1454-1465.

15. Domer, B. and I.F.C. Smith, An Active Structure that Learns. Journal of Computing in Civil Engineering, 2005. 19(1): p. 16-24.

16. Adam, B. and I.F.C. Smith, Reinforcement Learning for Structural Control. Journal of Computing in Civil Engineering, 2008. 22(2): p. 133-139.

17. Bel Hadj Ali, N. and I.F.C. Smith, Dynamic behavior and vibration control of a tensegrity structure. International Journal of Solids and Structures. 2010. 47(9): p. 1285-1296.

18. Pellegrino, S., Deployable structures. 2001: Springer.

19. Gantes, C.J., Deployable structures: analysis and design. 2001: WIT Press. 
20. Furuya, H., Concept of deployable tensegrity structures in space applications. International Journal of Space Structures, 1992. 7(2): p. 143-51.

21. Sultan, C. and R. Skelton, Deployment of tensegrity structures. International Journal of Solids and Structures, 2003. 40(18): p. 4637-4657.

22. Smaili, A. and R. Motro, Folding/unfolding of tensegrity systems by removal of selfstress. 2005, HAL - CCSD.

23. Pugh, A., An Introduction to Tensegrity. 1976: University of California Press.

24. Motro, R., B. Maurin, and C. Silvestri. Tensegrity Rings and the Hollow Rope. in IASS Symposium 2006, New Olympics, New Shells and Spatial Structures. 2006. Beijing.

25. Pellegrino, S. and C.R. Calladine, Matrix analysis of statically and kinematically indeterminate frameworks. International Journal of Solids and Structures, 1986. 22(4): p. 409-428.

26. Cevaer, F., J. Quirant, and J.-F. Dubé. Mechanical behaviour of a foldable tensegrity ring: parametric study. in 2011 Structural Engineering World Conferenc. 2011. Come.

27. Nguyen, D.A., Etude de comportement mécanique et du pliage d'un anneau de tenségrité à base pentagonale, in LMGC. 2009, Université de Montpellier II: Montpellier.

28. Moored, K.W. and H. Bart-Smith, Investigation of clustered actuation in tensegrity structures. International Journal of Solids and Structures, 2009. 46(17): p. 3272-3281.

29. Rhode-Barbarigos, L., et al., Designing tensegrity modules for pedestrian bridges. Engineering Structures. 2010. 32(4): p. 1158-1167.

30. Bel Hadj Ali, N., et al., Design optimization and dynamic analysis of a tensegritybased footbridge. Engineering Structures, 2010. 32(11): p. 3650-3659.

31. Rhode-Barbarigos, L., et al. Deployment analysis of a pentagonal tensegrity-ring module. in CSMA 2011: 10e colloque national en calcul des structures.

32. Rhode-Barbarigos, L., et al. Deployment of a Pentagonal Hollow-Rope Tensegrity Module. in IABSE-IASS Symposium 2011: Taller, Longer, Lighter. 2011. London.

33. Tibert, A.G. and S. Pellegrino, Review of form-finding methods for tensegrity structures. International Journal of Space Structures, 2003. 18(4).

34. Micheletti, A. and W.O. Williams, A marching procedure for form-finding for tensegrity structures. Journal of mechanics of materials and structures, 2006.

35. Juan, S.H. and J.M. Mirats Tur, Tensegrity frameworks: Static analysis review. Mechanism and Machine Theory, 2008. 43(7): p. 859-881.

36. SIA, Steel Construction. Vol. 263. 2003, Zurich: Swiss Society of Engineers and Architects.

37. SIA, Actions on Structures. Vol. 261. 2003, Zurich: Swiss Society of Engineers and Architects.

38. SIA, Basis of Structural Design. Vol. 260. 2003, Zurich: Swiss Society of Engineers and Architects.

39. Barnes, M.R., Form Finding and Analysis of Tension Structures by Dynamic Relaxation. International Journal of Space Structures, 1999. 14: p. 89-104. 
40. Bel Hadj Ali, N., L. Rhode-Barbarigos, and I.F.C. Smith, Analysis of clustered tensegrity structures using a modified dynamic relaxation algorithm. International Journal of Solids and Structures, 2011. 48(5): p. 637-647.

41. Motro, R., S. Najari, and P. Jouanna, Static and Dynamic Analysis of Tensegrity Systems, in ASCE International Symposium on Shells and Spatial Structures, Computational Aspects, Springer, Editor. 1986: New York. 